Rapid Reviews COVID-19•

\title{
Reviews of "Non-invasive Vagus Nerve Stimulation for Respiratory Symptoms of COVID-19: Results From a Randomized Controlled Trial (SAVIOR I)"
}

Abrahão Fontes Baptista ${ }^{1}$, Claire-Marie Rangon ${ }^{2}$

${ }^{1}$ Universidade Federal do ABC, ${ }^{2}$ Hospital Foundation Adolphe De Rothschild

Published on: Oct 28, 2021

License: $\underline{\text { Creative Commons Attribution } 4.0 \text { International License (CC-BY 4.0). }}$. 
To read the original manuscript, click the link above.

Summary of Reviews: This preprint claims that nVNS therapy has the potential to reduce pro-inflammatory cytokines in patients with COVID-19. Both reviewers agree on the importance of the issues it raised. They suggested the inclusion of cost-effectiveness analysis in the ongoing SAVIOR II trial.

Reviewer 1 (Abrahão Fontes Baptista, Ph.D) |

Reviewer 2 (Claire-Marie Rangon, MD, PhD) $|\mathrm{|c|}| \mathrm{C} \square$

RR:C19 Strength of Evidence Scale Key.

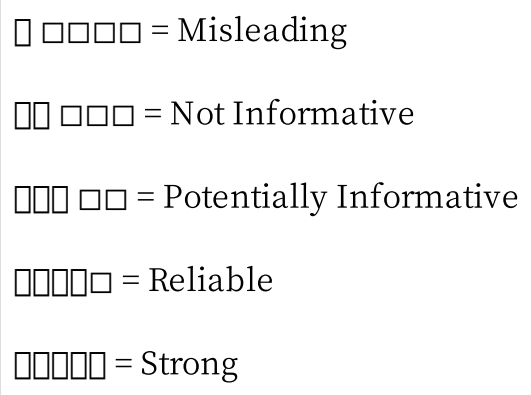

To read the reviews, click the links below. 